\title{
Extrañas coincidencias entre obras de marginados: las novelas picarescas y The Interesting Narrative of Olaudah Equiano
}

Resumen: Las novedades temáticas y compositivas que aportaron las primeras obras picarescas a la tradición literaria del momento constituyeron una vía alternativa en el asunto y modo de narrar que tendrían gran repercusión posterior para las letras occidentales. A pesar de que la estela de lo picaresco se ha probado para el caso de muchas obras extranjeras, todavía quedan tradiciones pendientes de estudio. Es por ello que el presente artículo se propone analizar de manera comparativa la obra fundacional de las Narrativas de esclavos, The Interesting Narrative of Olaudah Equiano, de acuerdo con las características y los rasgos entendidos como picarescos; buscando así establecer un posible panorama de influencias o coincidencias entre ambas tradiciones.

Palabras clave: picaresca, narrativas de esclavos, marginados, similitudes

Unexpected similarities within outsiders fictions: the Picaresque novel and the case of The Interesting Narrative of Olaudah Equiano

Abstract: The thematic and compositional characteristics provided by the early picaresque fictions into the literary tradition of the moment established an alternative path within the subject and narrative modes that will entail a revolution for Western literature. Although the picaresque trail was proved for many foreign literature creations, there are still to this day some traditions waiting for examination. It is the aim of this essay to analyse from a comparative perspective the foundational text of the Slave Narratives genre, The Interesting Narrative of Olaudah Equiano, based upon the recognition of picaresque features that may help provide a literary panorama of influences or coincidences shared by traditions.

Key words: picaresque novel, Slave Narratives, outsiders, similarities 


\section{INTRODUCCIÓN}

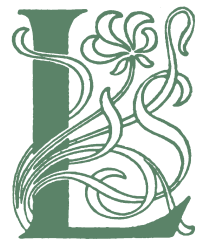

a novedad que supusieron los rasgos de las nuevas novelas picarescas en el panorama literario de la época configuró una revolución en la forma de narrar. Las nuevas obras del género rompían con la tradición tanto a nivel temático como formal, y tal fue así, que pronto muchos otros escritores, tanto nacionales como de fuera de nuestras fronteras, empezaron a imitar el novedoso modo de novelar. Técnicas como el ensartamiento, que trababa el total de la historia, supusieron una revolución dentro de la forma tradicional de la incipiente novela europea, cuyos máximos exponentes eran, por citar algunos, el Decamerón de Boccaccio, los Cuentos de Canterbury de Chaucer, o ya en suelo patrio, El libro del buen amor de Juan Ruiz o El conde Lucanor de Juan Manuel. No obstante, la novela picaresca abría camino también en lo que respecta al tema: el marginado alcanzaba la categoría de héroe literario.

No diremos que la temática marginal que aborda la obra sea novedosa ni dentro de España ni del continente, pues ya por aquel entonces en que el anónimo autor escribiese su libro, circulaban por Europa cuentos folclóricos y obras cuyos argumentos estaban protagonizados o versaban sobre marginados, según aparecen recogidos en los trabajos de Marcel Bataillon (1969), María Rosa Lida (1964) y Agustín Redondo (1979). Ejemplo de ello es el Liber Vagatorum alemán de 1510 o las obras posteriores a la publicación del Lazarillo de John Awedeley Fraternity of Vagabondes de 1561 y la de Thomas Harman A Caveat or Warning for Common Cursetors de 1566 en Inglaterra, amén de otras tantas publicadas por tales años a lo largo y ancho de los países del occidente europeo. Lo que sí apuntaremos es la novedad de la novela picaresca al respecto, pues no solo dará voz al marginado, sino que lo equiparará con los grandes personajes literarios del momento.

Toda esta novedad se constituyó como objeto de estudio propio por parte de la crítica nacional e internacional desde el momento en que pioneros como Fonger de Haan con su libro An Outline History of the Novela Picaresca in Spain (1895) empezasen a analizar las particularidades presentes en las obras del género. Si bien en un primer momento el esfuerzo crítico se encaminó 
hacia la figura del pícaro, tal es el caso de Frank Wadleigh Chandler en The Picaresque Novel in Spain (1899) o Alexander Parker en Literature and the Delinquent (1967), pronto se desvió la atención hacia la novedad que suponían los rasgos formales. Así, en Toward a Definition of the Picaresque (1971) Claudio Guillén explora el conjunto de elementos comunes a las obras picarescas con el fin de clarificar lo que era picaresco y sus novedades.

Es por ello que, a falta todavía de unanimidad crítica sobre el enfoque desde el que analizar los rasgos del género, pues muchos otros estudiosos sumaron sus esfuerzos desde multitud de diferentes disciplinas ${ }^{1}, \mathrm{y}$ frente a recientes propuestas que todavía deben ser analizadas por su potencial, como la de Florencio Sevilla (2001) sobre el carácter dialogístico del género, volveremos para nuestro estudio sobre el procedimiento inductivo de reconocimiento de los elementos comunes de las diferentes obras picarescas que fijase Lázaro Carreter en su ensayo Para una revisión del concepto novela picaresca publicado en 1968; modelo que a día de hoy continúa siendo la propuesta de mayor aceptación en la materia. De acuerdo con este estudio, el género picaresco no nacería de la primera novela picaresca, el Lazarillo, publicada hacia 1554 por su anónimo escritor, ni tampoco de la segunda, el Guzmán de Alfarache de Mateo Alemán, publicada en dos volúmenes en 1559 y 1604 respectivamente; sino mediante la asociación de una serie elementos comunes surgidos de ambos libros que serán reproducidos, con mayor o menor fortuna, en las posteriores novelas del género.

Así, siguiendo el ejemplo de Garrido Ardila (1999) en la comparación de estos rasgos picarescos para el caso de las incipientes novelas inglesas de Defoe, el presente artículo analizará las características de la poética picaresca según se encuentren o no presentes en The Interesting Narrative of Olaudah Equiano, una obra perteneciente a una tradición literaria de marginados como es la narrativa de esclavos. Esta obra, que entronca con la temática marginal europea, será comparada con las novelas de pícaros con el fin de establecer posibles similitudes a priori no esperadas.

1 Enfoques sociales como el de Bataillon (1969) o el de Molho (1972), definiciones etimológicas como las de Malkiel (1964), análisis legales e histórico-sociales de la sociedad de la época como los de Maravall (1976) intentan aportar luz sobre la materia como recoge Joseph L. Laurenti en su trabajo de 1973. 


\section{COMPARACIÓN DE LOS RASGOS TEMÁTICOS Y NARRATIVOS}

A la hora de fijar el análisis comparativo propuesto entre la poética picaresca y The Interesting Narrative of Olaudah Equiano es necesario abordar los rasgos establecidos por la crítica en función de su carácter temático o formal, pues es ahí donde decíamos reside el éxito del Lazarillo. La serie de rasgos elegidos para este estudio se limitará a la lista común desprendida del Lazarillo y el Guzmán según aparece recogida por Lázaro Carreter (1968):

1. Pícaro como héroe marginal de origen vil.

2. Autobiografía en primera persona.

3. Punto de vista único y dual.

4. Presentación del relato como explicación de un caso.

5. Narración cerrada.

6. Forma epistolar que presenta un destinatario o narratario.

7. Trabazón de toda la obra mediante eventos consecutivos unidos entre sí.

8. Servicio a varios amos.

9. Realismo.

10. Crítica social.

12. Tono irónico y satírico.

13.Variaciones de fortuna-adversidad.

Dentro de los rasgos temáticos destacamos el carácter marginal o outsider del protagonista. En la misma línea de Chandler (1899), Lázaro Carreter entiende que quizá el rasgo más reconocible y definitorio del género sea el pícaro. Este anti-héroe marginal presenta unas características que en buena medida son compartidas por todos los protagonistas de las novelas que conforman el canon picaresco. El pícaro es un buscavidas representado por un hombre común que, sin embargo, se encuentra al margen de la sociedad. De genealogía vil, encarna un deshonor que le marcará durante toda su vida 
en sus ansias de medro social. Según se recoge en los estudios del crítico americano, Chandler otorga al pícaro una condición ruin, una evolución psicológica de la inocencia a la maldad y una naturaleza solitaria y habladora.

Lázaro es el primer pícaro del género por ser el protagonista de la obra fundacional, el Lazarillo de Tormes. Nacido en el río del cual toma el apellido, era el hijo de un hombre que «tenía el cargo de proveer una molienda de una aceña» en la que «fue molinero más de quince años» (Lazarillo, 2006: 13). Declarado culpable de un hurto, confiesa y es perseguido de justicia hasta que se involucra en una campaña militar contra los moros, la de los Gelves, donde perderá la vida. Tras su muerte, la madre de Lázaro se ve desproveída, de ahí que tenga que frecuentar mesones y establos para ganarse la vida. Es en uno de ellos donde conocerá a un negro con el que tendrá su segundo hijo. Acusado también de robar, el hombre es enviado a prisión, y la madre se ve obligada a enviar a su hijo mayor, Lázaro, a servir a un ciego. Este será el principio del fin de la inocencia de Lázaro una vez separado de su familia y en las manos de un avispado maestro. Tras el comienzo de su vida picaresca, Lázaro servirá a diferentes amos viéndose envuelto en toda una serie de aventuras que darán forma a la personalidad del chico. Lázaro va abriendo poco a poco el ojo a un mundo de engaños en el que las apariencias no se ajustan a la realidad. Será desde su posición final como pregonero de Toledo que dé cuenta de las mañas de que se ha valido para alcanzar su estado, culminando la obra con una fuerte crítica social. No obstante, si bien Lázaro se sirve del engaño, siempre lo hará para sobrevivir, de donde no se desprende un natural mezquino ni malvado como el que puede observarse en posteriores héroes picarescos. Así, Lázaro encarna la vida de un hombre sin honra que se abre camino hasta alcanzar la "prosperidad y cumbre de buena fortuna» (Lazarillo, 2006: 135) amparado por el arcipreste con el que está amancebada su mujer.

Guzmán, por el contrario, es hijo de una mujer sevillana que, estando casada con su marido, mantiene un romance secreto con un hombre de Génova huido de Argel, lugar donde estaba casado y condenado por sus deudas económicas, con el que tendrá un hijo. Poco después del nacimiento de Guzmán, el marido muere y la madre se casa de nuevo con el verdadero padre de la criatura, que también fallece cuando el chico tan solo cuenta con doce años. No queda claro en el libro si su condición deshonrosa, así como cier- 
tas dificultades económicas, son los detonantes de su partida. De lo que no hay duda es de que, al contrario que Lázaro, Guzmán decide abandonar el seno familiar para darse a la aventura y descubrir mundo. Será durante estas aventuras que se descubra el natural del protagonista, pues hace gala de su felicidad siendo pícaro y realizando crímenes que ahora no son solo acometidos para sobrevivir, sino también para su divertimento. Así, los pequeños engaños y hurtos de Lázaro pronto quedan eclipsados ante las atrocidades de Guzmán durante sus viajes por Europa; crímenes estos que le llevarán a ser condenado por la justicia a remar en galeras hasta el final de sus días, momento en que finalmente dice arrepentirse de sus pecados y abraza la religión. No hay en Guzmán ningún medro social, pues si al comienzo de la obra se ve deshonrado por un origen vil, al final de la misma su condición empeorará por méritos propios. De tal modo, no existe en Guzmán la inocencia presente en Lázaro, siendo la evolución del pícaro de malvado a criminal. Y esto no es de extrañar, pues si el anónimo autor del Lazarillo buscaba la crítica social a través de las aventuras de un marginado, el creador del Guzmán se sitúa como predicador de los pecados y vicios de la humanidad a través de una atalaya humana.

Como vemos, las semejanzas entre ambos anti-héroes existen, pero las diferencias también son palpables. No obstante, para nuestro propósito, a pesar de que los protagonistas no sean idénticos, personifican a grandes rasgos una naturaleza picaresca de la que se constituirán como diferentes variantes. Esta situación debe ser tenida en cuenta en el análisis del protagonista de The Interesting Narrative of Olaudah Equiano, pues, si bien buscamos similitudes entre outsiders, tenemos que tener presente la inexistencia de un tipo totalmente igual y común a todas las novelas del género.

El protagonista The Interesting Narrative of Olaudah Equiano dice ser africano. Nacido en una familia acomodada, es el hijo de «one of those elders chiefs [...] styled Embrenché; a term, as I remember, importing the highest distinction» (Equiano, 2003: 32). No obstante, es raptado de su familia a la edad de once años «when an end was put to happiness» (Equiano, 2003: 46). Tras ser vendido luego como esclavo, Equiano es enviado a América donde padecerá muchos sufrimientos y tomará conciencia de su nueva condición como esclavo negro en un mundo dominado por blancos. De tal forma que, aunque su status inicial se opusiese al origen vil del pícaro, pronto quedará 
marginado y maltratado por la sociedad. Arrancado entonces del seno de su familia cuando todavía era un niño, la ingenuidad de Equiano definirá sus primeras aventuras en un mundo inhumano totalmente desconocido para él. Sin embargo, al igual que Lázaro, Equiano se da cuenta de la necesidad de medro en su condición; intentando así trabajar para poder comprar su libertad. Pero como explica Nichols en sus estudios en torno a la obra, ahora «the distingushing mark of the black picaroon is that his fate is determined not only by class but more importantly by caste [racial] status» (Nichols, 1985: 287). De natural bueno, incluso con aquellos que le tratan mal, Equiano pronto se da cuenta de los males de la sociedad, actuando así siempre con buenas maneras, pero buscando al final su propio interés al modo del pícaro. Tras muchas aventuras y decepciones que llevan al héroe a casi todas las esquinas del mundo, Equiano finalmente consigue comprar su libertad. Desde la posición de hombre respetable al final de la narrativa, se ve con pleno derecho a moralizar al lector sobre los males de la esclavitud y la necesidad de religión ante tantos pecados, de igual manera que Guzmán hiciese desde galeras contra los males de la sociedad amparado en la fe cristiana; dejando claro siempre que Guzmán predica por ejemplo ex-contrario dada su mala inclinación y Equiano sermonea con su propio ejemplo vital. Así, Angelo Costanzo explica al tratar del esclavo que «Equiano seems more like a preacher when he sermonizes against the devils of slavery and when his religious fervor impels him to see God's will in everything that happens to him» (Constanzo, 1987: 54).

Queda claro entonces que Equiano no comparte todas las características fijadas por Chandler (1899) para poder categorizarlo como héroe picaresco. Sin embargo, los personajes de Lázaro y Guzmán, en tanto que prototipos de la figura del pícaro que se desarrollará luego en las restantes novelas del género, ponen de relieve con su particular caracterización individual que Equiano contiene la mayor parte de los rasgos presentes en ambos héroes picarescos. Es también interesante notar que ni en Lázaro ni en Guzmán están representados todos estos constituyentes. Y lo que es más, de acuerdo con los datos ofrecidos, Equiano compartiría más elementos comunes con Lázaro y Guzmán que los dos últimos protagonistas entre sí.

Una vez observado el carácter marginal o outsider de los protagonistas dentro de los rasgos temáticos, pasaremos a analizar los rasgos formales de la poética picaresca dentro de The Interesting Narrative of Olaudah Equiano. 
El primer rasgo formal que hay que tener en cuenta, siguiendo la clasificación de Lázaro Carreter (1970), es la primera persona autobiográfica. Esta primera persona presente en la mayoría de obras picarescas muestra los hechos de una manera subjetiva basada en la experiencia del héroe. De tal subjetividad depende incluso la selección de material narrativo que se muestra en la obra, pues todo responde a un propósito final según veremos más adelante. Lo que está claro es que, salvando las distancias, la voz del narrador coincide con la del protagonista tanto en el Lazarillo, donde el pícaro nos cuenta sus fortunas y adversidades, como en el Guzmán, si bien en esta obra la primera persona autobiográfica deja entrever una multiplicidad de voces superpuestas. Cabe puntualizar aquí que la primera persona autobiográfica de los relatos no va unida necesariamente a una identificación real entre protagonista y escritor, siendo lo más común al conjunto de las novelas picarescas lo contrario. Por ello, a pesar de que Equiano diste en este sentido del Lazarillo, aunque todavía no se conozca su autor, y del Guzmán, escrito por Mateo Alemán, The Interesting Narrative of Olaudah Equiano se asemeja aquí al Estebanillo González, cuya vida es escrita por él mismo. Pero para nuestro estudio no hace falta ahondar en tales asuntos, pues lejos de polémicas sobre el carácter totalmente verídico del relato autobiográfico ${ }^{2}$, consideraremos tan solo los aspectos formales en tanto que de creaciones artísticas se trata. Así, de igual manera que Lázaro comenzase su relato presentándose con «Mi nacimiento fue dentro del río Tormes, por la cual causa tome el sobrenombre» (Lazarillo, 2006: 12), y Guzmán diese comienzo a su vida picaresca con «púseme el Guzmán de mi madre y Alfarache de la heredad adonde tuve mi principio. Con esto salí a ver mundo, peregrinando por él, encomendándome a Dios y buenas gentes, en quien hice confianza» (Alemán, 2003: 162), Equiano, tras dar ciertas notas geográficas de su país de origen, comienza su biografía de forma similar «I was born, in the year 1745, in a charming fruitful vale, named Essaka» (Equiano, 2003: 32).

Como seres marginales, su nombre importa tan poco que el Lazarillo tomará por apellido el río donde nació y Guzmán la heredad en la que vino al mundo. Equiano, por el contrario, recibirá varios nombres de esclavo, entre ellos el de Gustavus Vassa, que aparece también en el título de la narrativa,

2 La total veracidad del relato autobiográfico de Equiano atiende para muchos críticos a un recurso literario del que el escritor se sirve para el motivo final de su narración (Carretta, 2005: 308). 
pero al que otorgará un segundo plano respecto a su apelativo africano, que conservará como señal de identidad frente al anonimato degradante de la esclavitud.

Otra característica que se desprende directamente de este uso de la primera persona es la declaración de existencia de los protagonistas. Como personajes marginales y sin importancia real o literaria, su logro reside en conseguir alzar una voz individual dentro de la ignorada marisma social en la que se hallan. Y si bien esto no supone más en Lázaro y Guzmán, Equiano tendrá que ir más lejos y probar que su testimonio en forma de narrativa fue written by himself, pues como Jesús Benito y Ana M. ${ }^{a}$ Manzanas explican al respecto, «en este subtítulo está recogida, de forma telegráfica, la existencia misma del esclavo (sujeto existente, pues la autobiografía da fe de ello) y la contradicción misma de la esclavitud (pues el negro es esclavo por su incapacidad para leer y escribir o expresarse en forma literaria)» (Benito, 1994: 34).

También aparece unido al uso de la primera persona autobiográfica en las novelas picarescas el punto de vista único y dual. Los héroes picarescos cuentan sus aventuras pasadas desde la experiencia del hombre adulto que las recuerda. Esta particular perspectiva permite al narrador acercarse a la realidad más cruda, criticarla y moralizar al lector sobre el mundo que le rodea, pues su estado actual depende en última instancia de la experiencia acumulada durante las historias que presenta. Cabe decir que la moralización de los héroes y el propósito doctrinario de las obras picarescas apunta directamente a la influencia del género de la autobiografía cristiana a modo agustiniano como innegable, de ahí que parte de la crítica considere ciertos rasgos picarescos como propios del género autobiográfico; rasgos posteriormente aplicados también al estudio de las propias narrativas de esclavos ${ }^{3}$. Así, si bien Guzmán sermonea desde la penitencia en galeras a la que es condenado por sus pecados, Lázaro se limitará a presentar su caso tras lograr un empleo respetable, como ejemplo moral en un mundo en el que la moralidad es ciertamente dudosa. Comparando la situación de Equiano con la de Lázaro, las similitudes entre protagonistas vuelven a aparecer. Un Equiano ya experimentado y libre vuelve tras sus aventuras como hiciese Lázaro al contar

\footnotetext{
3 El uso de la primera persona aparece documentado en textos teológicos para la práctica religiosa y muchas de las consecuencias formales que impone se recogen tanto en las características propiamente picarescas como en las que Olney fijase para el caso de las narrativas de esclavitud (Olney, 1985, 152, 153).
} 
las suyas. Para alcanzar su estado actual ha tenido que sufrir los demonios de su realidad como esclavo, una situación que le otorga pleno derecho para criticarlos luego y poder servir al lector con su ejemplo.

No obstante, como arriba apuntábamos, los relatos picarescos responden a un propósito final o caso, que en palabras de Rico es «el asunto último de la novela» (Rico 1989: 24). A este rasgo se debe el impulso creativo del Lazarillo, pues es la razón por la que Lázaro le cuenta su historia a vuesa merced a modo de explicación de ciertos rumores que, sobre su vida, corren por Toledo. El caso del Guzmán, como bien apunta Ernesto Lucero Sánchez (2008), está basado en la conversión final del protagonista que, lleno de remordimiento, da cuenta de su vida para ejemplo y provecho del lector. Lo que está claro en ambas obras es que el caso sirve de excusa para que el pícaro vuelva sobre su vida hasta llegar al momento desde el que escribe, ya que necesita justificar su condición final. Comparando este rasgo de la poética picaresca con The Interesting Narrative of Olaudah Equiano, encontramos que su protagonista también cuenta su vida atendiendo a un propósito. Si bien hace apelaciones constantes al lector al solicitar «the indulgent attention of the public» (Equiano, 2003: 31), sabemos de sus propias palabras que el motivo de su narrativa es otro. De ahí que, aunque busque la atención del lector, puntualice que «if the following narrative does not appear sufficiently interesting to engage general attention, let my motive be some excuse for its publication» (Equiano, 2003: 31). Este motivo al que hace alusión Equiano está lejos de un mero relato de su vida como entretenimiento para el público, pues como Vincent Carretta explicase «the Narrative is formally framed by a petition to the Houses of Parliament that immediately follows the list [of subscribers], and the book virtually closes with an appeal to Queen Charlotte» (Carretta, 2003: 17). El testimonio del protagonista se sumaría así a las peticiones de la época contra la esclavitud desde la perspectiva de un «slaved African survivor of it» (Carretta, 2003: 14); atendiendo así, al igual que las novelas picarescas, a un propósito final que en el caso del género español recibe el nombre de caso.

Teniendo en cuenta este último rasgo, podemos entender que la narración picaresca quede cerrada. Una vez presentado el caso como justificación de la narración, la obra llega a su punto y final. Lázaro no tiene más que contarle a vuesa merced una vez ha satisfecho su curiosidad y ha dado cuenta sobre las habladurías entorno a su complicidad en el amancebamiento de su esposa como barragana del arcipreste, su benefactor. Guzmán pone fin a su relato 
tras explicar su estado actual y entregarse al lector como ejemplo. Y de forma similar, Equiano cerrará su historia una vez demuestre con su persona los males de la esclavitud tanto al público, como a las más altas instituciones británicas.

Descubrimos así la forma epistolar de los relatos, pues estos relatos cerrados presentan un caso a un destinatario específico, ya sea un protagonista interno de la obra, como es el caso del Lazarillo al escribir «y pues vuesa merced escribe se le escriba y relate el caso muy por extenso» (Lazarillo, 2006: 10), o sea el propio lector, como parece ser el caso del Guzmán ${ }^{4}$. En este punto la solución de Equiano pasa por un lugar intermedio. Además de compartir el carácter epistolar con las obras picarescas, el motivo de su misiva se dirige tanto a un lector general que necesita ser consciente de los males de la esclavitud, coincidiendo aquí con el Guzmán, como a un destinatario específico, a modo del arcipreste en Lázaro, que resulta ser «the British senators the dispersers of light» (Equiano, 2003: 233), ya que son ellos los que pueden poner fin a la lacra del comercio de esclavos.

Y para la narración de un caso en primera persona dirigido a un destinatario, lo primero que tiene que hacer el héroe es seleccionar el material atendiendo a su propósito final, de ahí que volvamos hacer hincapié en el carácter subjetivo que recorre las obras picarescas. Al ser preguntado Lázaro sobre el caso, el pícaro seleccionará solo aquellas aventuras que le sirvan para satisfacer la curiosidad de su destinatario y zanjar la cuestión de las habladurías. Guzmán hará lo mismo al escoger la gran cantidad de material misceláneo que presenta la obra, cuidándose siempre de que sirva a su propósito moralizador. En este punto el héroe de The Interesting Narrative of Olaudah Equiano seguirá los pasos de las obras anteriores, siendo incluso más claro al respecto al señalar que de lo narrado «almost every event of my life made an impression on my mind and influenced my conduct» (Equiano, 2003: 236). No obstante, este material necesita presentar una continuidad a modo de todo unitario, una trabazón que sostenga desde principio a fin el sentido último de las obras. No podía ser de otra forma que Lázaro, a la hora de explicar a su interlocutor el caso, escogiese remitirse al comienzo de su vida para poder seleccionar con mayor facilidad los eventos que creyó necesarios para

4 El destinatario de sus memorias no es ya un individuo real o fingido, sino un ente colectivo: el lector (Sobejano, 1959). 
satisfacerlo, al apuntar que «pareciome no tomalle por el medio, sino por el principio, porque se tenga entera noticia de mi persona» (Lazarillo, 2006: 11). Guzmán volverá sobre los pasos del Lazarillo al justificar su condición final de ejemplo ex-contrario moralizador incluso desde antes de su nacimiento, pues el primer capítulo se dedica en exclusiva a justificar su ascendencia vil mediante una breve exposición de la vida de sus progenitores. Es por este motivo que los eventos narrados en las obras picarescas son semejantes a las consecutivas letras de un nombre, pues presentan un orden específico que crea y explica su sentido. Y en este rasgo la obra de Equiano tampoco se queda atrás, pues la denuncia de la esclavitud no tendría el impacto deseado si no estuviese apoyada por los materiales atentamente seleccionados y perfectamente posicionados por Equiano para tal propósito. Es además con este fin, que en la narrativa de Equiano se recogen una serie de testimonios, datos y pruebas, a modo de para-texto, que sirven de apoyo veraz al fin último, motivo o caso del relato del autor, ante la posible cuestionabilidad entre los blancos de un relato escrito por un esclavo negro.

Dentro de las obras picarescas, el andamiaje compositivo de las aventuras que llevan a la explicación final del caso se articula en torno al servicio a varios amos. En Lázaro el proceso de maduración comienza con el servicio al ciego, amo al que siguen un clérigo, un escudero, un fraile, un buldero y un capellán, hasta que entra al servicio del arcipreste de San Salvador. Guzmán servirá de pinche de cocina y ayuda de un capitán, llegando incluso a servir a un cardenal y un embajador, para finalmente buscarse la vida por su cuenta. Todo este servicio a amos y búsqueda de medro social durante la obra, aunque con algunas matizaciones dada la condición del esclavo frente al pícaro, también se encuentra presente en The Interesting Narrative of Olaudah Equiano. Tras ser capturado, Equiano entra al servicio de diferentes amos hasta que consigue comprar su libertad. Al igual que las obras picarescas, la selección de amos responderá de nuevo al caso, abriendo al mismo tiempo la puerta a una crítica social de su época que se verá más adelante.

Otro rasgo fundamental de las obras picarescas es la factura realista con que están concebidas. La realidad que muestran los héroes se acerca mucho a la vida cotidiana de las personas llanas y a los problemas sociales a los que se enfrentan en su día a día. La realidad social que sirve de fondo a las aventuras de Lázaro y de Guzmán se corresponde con la España de los siglos 
de oro, momento en el que el imperio empieza a suponer un pesado yugo para un país en el que las desigualdades entre clases se hacen cada día más patentes. Surgen entonces toda una serie de personajes marginales dedicados al engaño y la estafa, ya no con el fin de hacerse ricos, sino de sobrevivir. Este mundo será pintado con todo lujo de detalles en el Lazarillo, según se observa en la descripción de la casa del escudero, o en el Guzmán, si bien aquí la prédica moral eclipsa en gran medida el lenguaje realista de los pasajes en los que se narra la vida del pícaro. Lázaro nos cuenta por ejemplo que el escudero «abrió su puerta y entramos en casa; la cual tenía la entrada obscura y lóbrega de tal manera que parece que ponía temor a los que en ella entraban, aunque dentro della estaba un patio pequeño y razonables cámaras» (Lazarillo, 2006: 74). Y si bien no son descripciones totales y objetivas al gusto decimonónico, la subjetividad de la mirada realista del pícaro va centrando la atención en toda una serie de elementos que, a la par que el lector, le ayudan a desentrañar lo que se oculta tras las apariencias. Este lenguaje realista estará también presente en la narrativa de Equiano, palpándose en la obra un realismo aun más objetivo que en las obras picarescas para dar mayor credibilidad a su testimonio como esclavo. Así, describe las casas de su país natal en la siguiente manera «In our buildings we study convenience rather than ornament. Each master of a family has a large square piece of ground, surrounded with a moat or fence, or enclosed with a wall made of red earth tempered; which, when dry, is as hard as brick» (Equiano, 2003: 36). No obstante, servirá además de contrapunto a las expectativas del protagonista, a la vez que del lector, frente a la realidad de lo narrado; pues de igual manera al escudero en el Lazarillo, los esclavistas cristianos se sustentaban en leyes trasnochadas y meras apariencias que servían tan solo para ocultar su verdadero ser.

Todo este realismo, tanto de las obras picarescas, como de The Interesting Narrative of Olaudah Equiano, responde así a una labor de crítica social por parte de sus protagonistas. La realidad decadente de los siglos XVI y XVII se vuelve campo de batalla para muchos ciudadanos que luchan por sobrevivir en una sociedad de apariencias, sin valores y corrupta. Jesús Benito y Ana $\mathrm{M}^{\mathrm{a}}$ Manzanas dirán al respecto que el pícaro y el esclavo «observan y meditan sobre una sociedad que niega su humanidad», de ahí que ambos se vean «obligados a adoptar todas las estratagemas y trucos a su alcance, y juegan los papeles más diversos acordes con las necesidades de cada momento». 
(Benito, 1994: 29,30) No existe entonces espacio social propio para el marginado, el cual, como Lázaro, deberá valerse del engaño y la conformidad para alcanzar la cumbre de su buena fortuna, dejando patente durante su discurso la dificultad que ello le supone en comparación con «los que heredaron nobles estados [...] pues Fortuna fue con ellos parcial, y cuanto más hicieron los que, siéndoles contraria, con fuerza y maña remando, salieron a buen puerto» (Lazarillo, 2003: 11). A esta crítica atiende la selección de amos, todos tipos representativos de esa España desmoralizada y agonizante, que todavía se rige por el trasnochado concepto de la honra. Tal situación es idéntica tanto en el Guzmán como en el resto de obras picarescas, estando no obstante la crítica social orientada en sentido contrario en algunas de ellas debido a la condición y mentalidad del escritor ${ }^{5}$. Difícil resulta entonces extrapolar la situación social de España por aquellos años a la Inglaterra de la narrativa de Equiano. Allí no existían conceptos como el de la honra, ni se castigaba el trabajo manual. No obstante, muchos de los problemas más acuciantes del siglo de oro español aparecerán en el país británico durante el siglo XVIII. Estudios críticos sobre tales periodos en ambos países, como el de J. H. Elliot Empires of the Atlantic World: Britain and Spain in America 1492-1830, ponen de manifiesto estas semejanzas. Las clases más desfavorecidas se encontraban al margen de la sociedad, y rogues, delincuentes y maleantes convivían con la nueva figura del esclavo. Así, a pesar de ser el esclavo diferente al pícaro por su condición de hombre no libre, vive un conflicto similar al de éste durante sus aventuras. Tal le sucede a Equiano, el cual, de igual manera que Lázaro, luchará por medrar y conseguir su libertad, no llegando nunca, como le sucede al de Tormes, a igualarse con aquellos con los que se codea una vez llegado a su cumbre.

Sin embargo, a pesar de presentar un corte realista, gracias a la perspectiva dual con la que el narrador cuenta los hechos, un contrapunto irónico y humorístico recorre todas las obras. Los héroes picarescos, como decíamos, vuelven sobre su vida para justificar su situación final, de ahí que el pícaro maduro reviva sus aventuras satirizando la ingenuidad de la que hacía gala cuando ocurrieron tales episodios. Tal ironía, como no podía ser de otra forma, se va abandonando a la largo de la obra, pues las vivencias del héroe le

\footnotetext{
5 El caso más representativo de la defensa de la sociedad estamental española de la época es el Buscón de Quevedo, el cual dirige su crítica contra aquellos personajes de origen vil que pretender medrar e igualarse con aquellos de condición noble (Redondo, 1974).
} 
llevan a madurar y endurecerse respecto a las cuestiones de la vida. Dentro de estos pasajes destacan en el Lazarillo el robo del vino al ciego, el arca del cura o el entierro del muerto al que se va a dar sepultura, a su parecer, en casa del escudero. Los pasajes que llevan a diversión son otros tantos en el Guzmán, y tanto es así, que Mateo Alemán tuvo que advertir al lector «haz como leas lo que leyeres y no te rías de la conseja y se te pase el consejo» (Alemán, 2009: 111). Y si bien en Equiano el tono fundamental de la obra resulta muy solemne y serio en su conjunto, se le escapan al autor ciertos pasajes de comicidad basados en la ingenuidad e inexperiencia del héroe. Nos vienen a la cabeza las frustradas expectativas de heredar fortuna junto al Capitán Farmer, la visión primera que de la nieve tiene el protagonista al creer que «somebody in the night had thrown salt all over the deck» (Equiano, 2003: 67), o el momento en que espera respuesta del libro al explicar cómo

«had often seen my master and Dick employed in reading; and I had a great curiosity to talk to the books, as I thought they did; and so to learn how all things had a beginning: for that purpose I have often taken up a book, and have talked to it, and then put my ears to it, when alone, in hopes it would answer me; and I have been very much concerned when I found it remained silent». (Equiano, 2003: 68) ${ }^{6}$

Finalmente, el último rasgo a considerar es la oposición fortunas-adversidades por el que se rigen las aventuras de los protagonistas. La vida del pícaro está, tanto en el Lazarillo como en el Guzmán, llena de dificultades. Lázaro hace referencia a su vida en el prólogo de la siguiente manera, «confesando yo no ser más sancto que mis vecinos [...] vean que vive un hombre con tantas fortunas, peligros y adversidades» (Lazarillo, 2003: 8). Pero ya el anónimo autor de la obra dejaba la cuestión zanjada al titular la novela como Vida de Lazarillo de Tormes: $y$ de sus fortunas y adversidades; quedando el destino del pícaro desde el principio condicionado. En el caso del Guzmán, a pesar de que no existe alusión explícita a las fortunas y adversidades durante el prólogo o la novela, el pícaro se verá envuelto en ascensos y caídas que a dicha dualidad responden. Sorprendentemente una vez más, The Interesting Narrative of Olaudah Equiano comparte con el Lazarillo la alusión clara a «all the adversity and variety of fortune I have since experience» (Equiano, 2003: 46).

6 Episodio recurrente en muchas otras narrativas del género bajo el apelativo de "the talking book", que ya se encuentra recogido en las narrativas de esclavos anteriores a la obra de Equiano (Gates, 1988: 127169). 


\section{CONCLUSIONES}

Tras el detenido análisis comparativo de los rasgos temáticos y formales de las obras fundacionales del género picaresco sobre The Interesting Narrative of Olaudah Equiano, se descubre una quasi-total coincidencia que acercaría una obra tan dispar como la de Equiano al género picaresco. La hipótesis de partida de este estudio buscaba las posibles semejanzas entre obras cuyos protagonistas comparten de entrada la condición de marginados u outsiders, y las conclusiones que se desprenden ofrecen una serie de similitudes a la espera de valoración.

The Interesting Narrative of Olaudah Equiano fue publicada en Inglaterra en 1794 y se engloba dentro de las Slave Narratives o narrativas de esclavos, género del que sería la obra más representativa. Estas narrativas no guardarían de entrada relación alguna con el género picaresco, de ahí que una primera opción de estudio sea considerar las semejanzas como fruto de una convergente coincidencia. Ambas tradiciones, tanto la picaresca como la de las narrativas de esclavos, se sirven de los principales rasgos de la autobiografía para sus propósitos literarios, de donde puede desprenderse que las soluciones a las que llegan tanto los autores españoles como los anglosajones a nivel temático y formal sean fruto de un proceso similar y esperado, surgido de un contexto y unas imposiciones formales y de contenido determinado por censores y abolicionistas para cada caso. ${ }^{7}$

Sin embargo, las indicaciones realizadas por críticos como Charles $\mathrm{H}$. Nichols (1985) ofrecen una segunda posibilidad de influjo o trasvase entre tradiciones literarias; una teoría que estudiosos como Costanzo apoyan al mantener que «one tradition Equiano used was that of the young individual picaresque hero or anti-hero, a popular subject in the eighteen century» en Inglaterra, ya que «the picaresque tradition can be traced from the Spaniards of the sixteenth century, to the Elizabethan prose writers, and to the eighteen century novelists that include Swift, Defoe, Smollet and Fielding» (Costanzo, 1987: 46).

Desafortunadamente para nosotros no existe documento alguno ni datos empíricos que corroboren tales aseveraciones. Tan solo podemos anotar el

7 Resultan muy clarificadores en este punto los esfuerzos realizados por Garrido Ardila por desvincular los rasgos a su parecer propios del género picaresco con respecto a los del género autobiográfico (2008). 
hecho de que fue en Inglaterra donde surgió la primera traducción del $L a$ zarillo en 1568 de la pluma de David Rowland, el éxito sin precedentes de la traducción de 1622 de James Mabbe del Guzmán de Alfarache, así como las siete re-ediciones que de esta obra vieron la luz en los años siguientes. No cabe duda entonces del conocimiento picaresco que debía existir en el país anglosajón. Lo que no podemos confirmar es, sin embargo, hasta qué punto influyeron las obras del género español en las narrativas de esclavos de los escritores ingleses y americanos del momento. Sirvan así las conclusiones de este estudio al debate.

\section{REFERENCIAS BIBLIOGRÁFICAS}

Alemán, Mateo (2009), Guzmán de Alfarache I-II, José María Micó (ed.), Madrid, Cátedra.

ANónimo (2006), Lazarillo de Tormes, Francisco Rico (ed.), Madrid, Cátedra.

Ardila, Juan Antonio G. (1998), El género picaresco en la crítica literaria, Madrid, Biblioteca Nueva.

- (1999), «La tradición picaresca española en Inglaterra» en Bulletin of Hispanic Studies, 76.4, págs. 453-470.

Batalllon, Marcel (1969), Pícaros y picaresca, Madrid, Taurus.

CArretta, Vincent (2005), Equiano. The African. Biography of a Self Made Man, Georgia, University of Georgia Press.

Costanzo, Angelo (1987), Surprizing Narrative, Conecticut, Greenwood Press.

ElLIOTT, John. H. (2006), Empires of the Atlantic World: Britain and Spain in America 1492-1830, New Haven, Yale University Press.

EQuiano, Olaudah (2003), The Interesting Narrative of the Life of Olaudah Equiano, or Gustavus Vassa, the African, Vincent Carretta (ed.), London, Penguin Books.

- (1994), «Introducción», La Interesante narración de Olaudah Equiano o Gustavus Vassa, el africano escrita por si mismo: capítulo 2 texto bilingüe, Jesús Benito y Ana Ma. Manzanas (trad.), León, Universidad de León. 
Gates, Henry Louis Jr. (1988), The Signifying Monkey, Nueva York, Oxford University Press.

GuILLÉN, Claudio (1971), «Toward a Definition of the Picaresque», en Literature as System, Princeton, Princeton University Press, págs. 109-257.

Guillén, Claudio y LÁzaro Carreter, Fernando (1983), «Constitución de un género: la novela picaresca», en Francisco Rico (ed.), Historia y crítica de la literatura español. Siglos de Oro: Barroco, Barcelona, Crítica, págs. 468-474.

HaAn, Fonger de (1895), An Outline History of the Novela Picaresca in Spain, Baltimore, Johns Hopkins University, https://archive.org/details/outlineofhistory00deha (accedido el 29 de marzo de 2016).

LÁzARo CARreter, Fernando (1970), «Para una revision del concepto "novela picaresca"», en Biblioteca Virtual Miguel de Cervantes, http://www. cervantesvirtual.com/obra-visor/para-una-revision-del-concepto-novela-picaresca/html/aaae16f4-a0fe-11e1-b1fb-00163ebf5e63_4.html\#I_0_ (accedido el 12 de enero de 2017).

LAURENTI, Joseph L. (1973), Bibliografía de la literatura picaresca; desde sus orígenes hasta el presente, Metuchen, Scarecrow Press.

Lucero SÁnchez, Ernesto (2008), «La función fática en el Guzmán de Alfarache», en TONOS Revista Filológica de Estudios Hispanos, 16 Diciembre, https://www.um.es/tonosdigital/znum16/ secciones/estudios-9.htm (accedido el 13 de enero de 2017).

Lida de Malkiel, María Rosa (1964), «Función del cuento popular en el Lazarillo de Tormes», en Actas del Primer Congreso de Hispanistas, Oxford, págs. 349-359.

Nichols, Charles H. (1985). «The Slave Narrators and the Picaresque Mode: Archetypes for Modern Black Personae», en Charles T. Davis and Henry Louis Gates (eds.), The Slave's Narrative, Oxford, Oxford University Press, págs. 283-298.

Olney, James (1985), «"I Was Born”: Slave Narratives, Their Status as Autobiography and as Literature», en Charles T. Davis and Henry Louis Gates 
(eds.), The Slave's Narrative, Oxford, Oxford University Press, págs. 148175.

PARKer, Alexander A. (1967), Literature and the Delinquent. The Picaresque novel in Spain and Europe 1599-1753, Edinburgh, University Press.

REDONDO, Agustín (1979), «Pauperismo y mendicidad en Toledo en época del Lazarillo», en H. Bonneville (ed.), Hommage des hispanistes français a Noël Salomon, Barcelona, págs. 703-724.

Rico, Francisco (1989), La novela picaresca y el punto de vista, Barcelona, Seix Barral.

RodríGuez LuIs, Julio (1990), «El enfoque comparativo de la literatura picaresca», Centro Virtual Cervantes, http://cvc.cervantes.es/literatura/aiso/ pdf/02/aiso_2_2_040.pdf (accedido el 13 de enero de 2017).

Sevilla Arroyo, Florencio (2001), La novela picaresca española, Madrid, Castalia.

Sobejano, Gonzalo (1959), «De la intención y valor del “Guzmán de Alfarache"», en Biblioteca Virtual Miguel de Cervantes, http://www.cervantesvirtual.com/obra-visor/de-la-intencin-y-valor-del-guzmn-dealfarache-0/html/021a3804-82b2-11df-acc7-002185ce6064_6.html\#I_0_ (accedido el 13 de enero de 2017).

Turner Gutiérrez, Ellen (1995), The Reception of the Picaresque in the French, English, and German Traditions, New York, Peter Lang Publishing.

VAíllo, Carlos (1983), «La novela picaresca y otras formas narrativas», en Francisco Rico (ed.), Historia y crítica de la literatura español. Siglos de Oro: Barroco, Barcelona, Crítica, págs. 448-467.

Wadleigh Chander, Frank (1899), An Episode in the History of the Novel, London, MacMillan, https://archive.org/stream/romancesroguery00changoog\#page/n7/mode/2up (Accessed 29 March 2014).

Walvin, James (1998), An African's Life. The Life and Times of Olaudah Equiano, 1745-1797, New York, Continuum. 


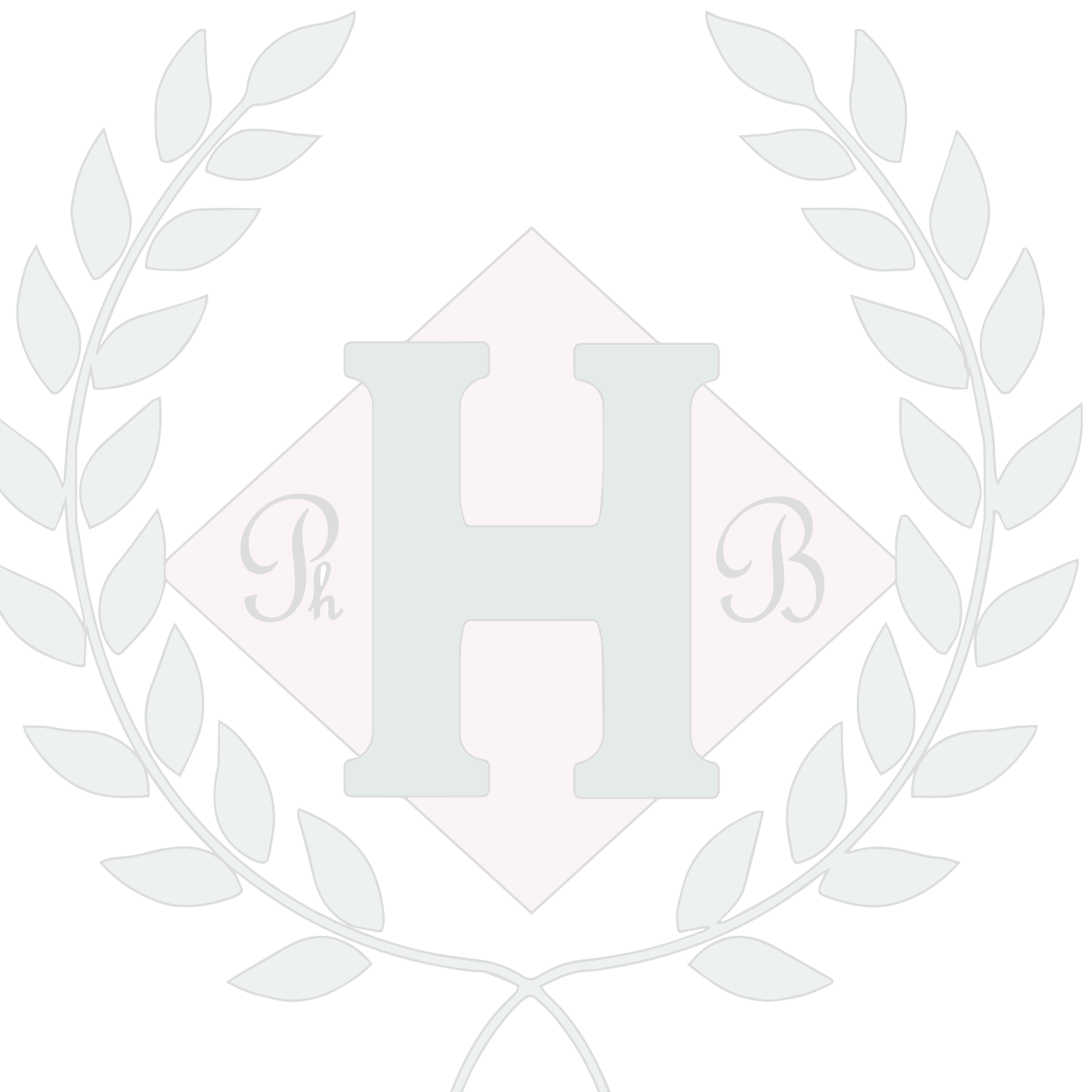

